\title{
Induction of Circulating Myelin Basic Protein and Proteolipid Protein-specific Transforming Growth Factor- $\beta 1-$ secreting Th3 T Cells by Oral Administration of Myelin in Multiple Sclerosis Patients
}

\author{
Hikoaki Fukaura, Sally C. Kent, Matthew J. Pietrusewicz, Samia J. Khoury, Howard L. Weiner, and David A. Hafler \\ Center for Neurologic Diseases, Department of Neurology, Brigham and Women's Hospital and Harvard Medical School, Boston, \\ Massachusetts
}

\begin{abstract}
Oral administration of antigen is a long recognized method of inducing systemic immune tolerance. In animals with experimental autoimmune disease, a major mechanism of oral tolerance triggered by oral administration of antigen involves the induction of regulatory $T$ cells that mediate active suppression by secreting the cytokine TGF- $\beta 1$. Multiple sclerosis (MS) is a presumed T cell-mediated Th1 type autoimmune disease. Here, we investigated whether in MS patients oral myelin treatment, containing both myelin basic protein (MBP) and proteolipid protein (PLP), induced antigen specific MBP or PLP reactive T cells that either secreted IL-4, TGF- $\beta 1$, or alternatively did Th1 type sensitization occur as measured by IFN- $\gamma$ secretion. Specifically, 4,860 short-term $\mathrm{T}$ cell lines were generated to either MBP, PLP, or tetanus toxoid (TT) from 34 relapsing-remitting MS patients: 17 orally treated with bovine myelin daily for a minimum of $2 \mathrm{yr}$ as compared to 17 nontreated patients. We found a marked increase in the relative frequencies of both MBP and PLP specific TGF- $\beta 1$-secreting T cell lines in the myelin treated MS patients as compared to non-treated MS patients (MBP $P<0.001$, PLP $P<0.003$ ). In contrast, no change in the frequency of MBP or PLP specific IFN- $\gamma$ or TT specific TGF- $\beta 1$ secreting T cells were observed. These results suggest that the oral administration of antigens generates antigen specific TGF- $\beta 1$ secreting Th3 cells of presumed mucosal origin that represent a distinct lineage of $T$ cells. Since antigen-specific TGF- $\beta 1$ secreting cells localize to the target organ and then suppress inflammation in the local microenvironment, oral tolerization with self antigens may provide a therapeutic approach for the treatment of cell-mediated autoimmune disease which does not depend upon knowledge of the antigen specificity of the original $\mathrm{T}$ cell clone triggering the autoimmune cascade. (J. Clin. Invest. 1996. 98:70-77.) Key words: demyelination • oral tolerance $\cdot$ autoantigen $\cdot$ regulatory cytokines
\end{abstract}

Address correspondence to David A. Hafler, M.D., Center for Neurologic Diseases, 221 Longwood Ave., Boston, MA 02115. FAX: 617732-7787; E-mail: hafler@CND.BWH.Harvard.edu

Received for publication 27 November 1995 and accepted in revised form 4 April 1996.

J. Clin. Invest.

(C) The American Society for Clinical Investigation, Inc.

0021-9738/96/07/70/08 \$2.00

Volume 98, Number 1, July 1996, 70-77

\section{Introduction}

Multiple sclerosis (MS $)^{1}$ is a chronic inflammatory disease characterized by lymphocytic infiltration and demyelination in the central nervous system (CNS) thought to be initiated by Th1 type $\mathrm{T}$ cells recognizing myelin components of the CNS $(1,2)$. Alterations in regulation of immune responses are found in patients with the disease, though these defects are not well defined $(1,2)$. Experimental autoimmune encephalomyelitis (EAE), a model for a cell mediated Th1 type autoimmune CNS disease, shows pathologic similarities to MS and is induced by activated $\mathrm{T}$ cells recognizing myelin basic protein (MBP) (3), proteolipid protein (PLP) (4) or myelin-oligodendrocyte glycoprotein (MOG) (5). In the EAE model, activated, $\mathrm{CD}^{+}$myelin reactive $\mathrm{T}$ cells secreting the cytokines interleukin-2 (IL-2), interferon-gamma (IFN- $\gamma$ ), tumor necrosis factor- $\alpha$, and lymphotoxin migrate into the CNS and initiate a cascade of events that can lead to clinical paralysis in the animals. Spontaneous recovery is associated with secretion of IL-4, IL-10, and transforming growth factor-beta 1 (TGF- $\beta 1$ ) (6).

The oral administration of antigen is a long recognized method of inducing tolerance by suppressing systemic $\mathrm{T}$ cell mediated immune responses $(7,8)$. More recently, oral tolerance has been used to suppress experimental autoimmune diseases, including EAE $(9,10)$, collagen $(11,12)$, and adjuvantinduced arthritis (13), uveitis (14), and spontaneous diabetes in the nonobese mouse (15). Three distinct mechanisms have been elucidated for the systemic-antigen-specific immune suppression associated with oral tolerance. In the first two mechanisms, feeding high doses of antigen induces either deletion (16) or anergy $(17,18)$ of antigen-specific cells presumably by providing a strong $\mathrm{T}$ cell receptor signal to antigen specific $\mathrm{T}$ cells. In contrast, feeding multiple low doses of antigen induces regulatory $\mathrm{T}$ cells that mediate suppression by secreting the cytokines IL-4, IL-10, and TGF- $\beta 1$ (19-21). Specifically, T cell clones isolated from the mesenteric lymph nodes of mice orally tolerized with low doses of MBP were structurally identical to Th1 encephalitogenic $\mathrm{CD}^{+}$clones in $\mathrm{T}$ cell receptor usage, MHC class II restriction and epitope recognition while secreting IL-4, IL-10, and TGF- $\beta 1$ (20). These clones suppressed ongoing EAE induced by either MBP or PLP. This indicates that antigen-specific regulatory $T$ cells generated in the gut can migrate to the target organ and suppress ongoing inflammatory reactions in an antigenic nonspecific fashion, a phenomena termed bystander suppression $(19,20)$.

1. Abbreviations used in this paper: APC, antigen-presenting cell; CNS, central nervous system; EAE, experimental autoimmune encephalomyelitis; MBP, myelin basic protein; MS, multiple sclerosis; PLP, proteolipid protein; TT, tetanus toxoid. 
These investigations in experimental models of autoimmune diseases have led to a series of phase I/II double-blind clinical trials of oral tolerance in subjects with MS, rheumatoid arthritis, and uveitis. We reported previously no adverse toxicity or side effects in a pilot double-blind trial involving 30 relapsing-remitting MS patients receiving daily capsules of bovine myelin containing both MBP and PLP proteins for $1 \mathrm{yr}$. The frequency of $\mathrm{T}$ cells reactive with MBP from myelintreated MS individuals were reduced as compared to nonmyelin treated control MS individuals. Clinically, there was a tendency for the treated group to have fewer exacerbations, especially in the subgroup of DR2-males (22). A statistically significant clinical effect after oral administration of type II collagen has been shown in the subjects with rheumatoid arthritis (23). The clinical efficacy of oral myelin tolerization in subjects with MS is presently under phase III investigation in a multicenter, 504 patient, randomized, double-blind clinical trial (24).

Based on the identification of antigen-reactive TGF- $\beta 1$ secreting $\mathrm{T}$ cells in mice that were orally tolerized to MBP, we wished to determine whether the oral administration of myelin to MS patients induced antigen-specific MBP or PLP reactive $\mathrm{T}$ cells that either secreted IL-4, TGF- $\beta 1$, or alternatively did Th1 type sensitization occur as measured by IFN- $\gamma$ secretion. As MS patients are known to have poorly defined defects in the generation of suppression $(1,2)$, it was particularly important to determine whether the prolonged oral administration of myelin autoantigens would result in the desired TGF- $\beta 1$ secreting cells or instead would such treatment provoke unwanted Th1 type response to the orally administered myelin antigens. Despite numerous studies of oral tolerance in animals, such questions can only be addressed in patients with the disease who are given oral autoantigens over prolonged periods of time. Our results demonstrate no Th1 sensitization after prolonged oral antigen administration in MS patients; instead, MBP and PLP reactive TGF- $\beta 1$ secreting cells were induced.

\section{Methods}

Patients. 17 relapsing-remitting MS patients from the continuation study of the phase I/II oral myelin trial were examined (24). These patients had been orally dosed with $300 \mathrm{mg}$ bovine myelin (Myloral $^{\mathrm{TM}}$ ) daily for at least $2 \mathrm{yr}$. The preparation contained $\sim 7.5 \mathrm{mg}$ of MBP and $15 \mathrm{mg}$ of PLP and was supplied to patients by AutoImmune, Inc. (Lexington, MA). The open label clinical results of the continuation study have been reported separately (24). 17 relapsingremitting MS patients who did not receive bovine myelin were examined as controls. The average disease duration for oral myelin-treated group was 11.8 $\pm 4.3 \mathrm{yr}$ (age: $37.8 \pm 4.8$ ) and for control was $11.6 \pm 8.7 \mathrm{yr}$ (age: $37.1 \pm 5.7$ ). MS patients were not treated with immunosuppressive drugs or Betaseron ${ }^{\mathrm{TM}}$ in the past or with steroids within 3 mo of blood sampling. These investigations were approved by the human subjects committee of the Brigham and Women's Hospital (Boston, MA).

Antigens. Human MBP was purified from the white matter of the human brain by the method previously described and was provided by AutoImmune, Inc. (25). Bovine PLP was purified as previously described (26). Tetanus toxoid (TT) was obtained in purified form from the Massachusetts Public Health Laboratory (Boston, MA).

Antigen-specific T cell lines. Peripheral blood mononuclear cells (PBMC) were isolated from heparinized venous blood by FicollHypaque density gradient, washed twice with HBSS, counted, and resuspended in media containing $10 \%$ autologous serum (collected from each patient and heat-inactivated; this serum was used throughout the experiment for each patient) in RPMI 1640, $10 \mathrm{mM}$ Hepes buffer, $2 \mathrm{mM}$ L-glutamine, and $100 \mathrm{U} / 100 \mu \mathrm{g}$ per ml penicillin/streptomycin. All media and components were purchased from BioWhittaker (Walkersville, MD). PBMC from each patient were frozen in $10 \%$ DMSO/FBS (from Sigma Chemical Co., St. Louis, MO and BioWhittaker, respectively) at $-70^{\circ} \mathrm{C}$ and were used as antigen-presenting cells for the remainder of the assay. PBMC from each patient were pulsed with antigen; $1.2 \times 10^{7} \mathrm{PBMC}$ in $1.2 \mathrm{ml}$ were pulsed with either MBP $(50 \mu \mathrm{g} / \mathrm{ml})$, bovine PLP $(50 \mu \mathrm{g} / \mathrm{ml})$, or TT $(12 \mathrm{Lf} / \mathrm{ml})$ for $2 \mathrm{~h}$ at $37^{\circ} \mathrm{C}$, washed in media twice with $10 \%$ autologous serum and then seeded in 96-well U-bottom plates (CoStar Corp., Cambridge, MA) at $2 \times 10^{5}$ cells/well (with total vol of $200 \mu \mathrm{l} /$ well). On day 7 , each well was restimulated with the primary antigen as used at day 0 . Autologous PBMC were pulsed with antigen by incubating $10^{7} \mathrm{PBMC}$ in 1 $\mathrm{ml}$ of media with antigen at a concentration of $100 \mu \mathrm{g} / \mathrm{ml}$ (MBP or $\mathrm{PLP}$ ) or $10 \mathrm{Lf} / \mathrm{ml}$ (TT) for $2 \mathrm{~h}$ at $37^{\circ} \mathrm{C}$, washed twice in media, and then irradiated with 5,000 rad. $2 \times 10^{5}$ antigen pulsed PBMC were added to each well. On day $9,100 \mu$ media was removed from each well and $100 \mu \mathrm{l}$ of media with IL-2 (T cell supernatant derived from Phytohemagglutinin-P stimulated human PBMC, final concentration per well, $5 \% \mathrm{vol} / \mathrm{vol}$ ) (Collaborative Biomedical Products, Bedford, MA) and rIL-4 (2.5 U/ml, final concentration/well) (Boehringer Mannheim, GmbH, Mannheim, Germany) was added to the wells.

On day 14, a split well assay was performed. Each well was split into four wells: two received $10^{5}$ autologous, antigen-pulsed, washed, and irradiated cells each, and two received $10^{5}$ autologous, non-antigen-pulsed, washed, and irradiated cells each. All antigen pulsing, washing, and irradiation was performed as described above for the day 7 antigen pulse. Final well volume was $200 \mu l$. Supernatants were collected after $24 \mathrm{~h}$ for cytokine measurement of IL- 4 and IFN- $\gamma$ by ELISA. The lines were cultured for an additional $72 \mathrm{~h}$ in $150 \mu \mathrm{l} /$ well of serum free media (X-Vivo 20; BioWhittaker), and supernatants were then collected for measurement of TGF- $\beta 1$. Each cell line was then pulsed with $1 \mu \mathrm{Ci} /$ well of ${ }^{3} \mathrm{H}$-thymidine during the last $18 \mathrm{~h}$ of culture and subsequently harvested by an automated cell harvester (Beta plate 1295-004; Wallac, Gaithersburg, MD). ${ }^{3} \mathrm{H}$-thymidine uptake was measured in a beta scintillation counter (Beta plate 1205; Wallac). As previously described, antigen-reactive lines were defined by exhibiting both a stimulation index of greater than 3 and a $\triangle$ CPM of $>500$. The relative frequency of antigen-reactive lines were calculated by dividing the numbers of wells positive for reactivity, as defined above, by the total number of lines generated after stimulation with that antigen (22). Each well in the 96-well plate yielded a growth positive well under these culture conditions that could be examined for antigen reactivity.

Cytokine assays. Cytokines produced by $\mathrm{T}$ cell lines were assayed by ELISA. To measure IL-4, a capture ELISA method was used as follows: Immulon 4 microtiter plates (Dynatech, Chantilly, VA) were coated with capture mAb (Pharmingen, San Diego, CA) at $1 \mu \mathrm{g} / \mathrm{ml}$ diluted in $0.1 \mathrm{M} \mathrm{NaHCO}_{3}\left(\mathrm{pH} \mathrm{8.2)}\right.$, and incubated at $4^{\circ} \mathrm{C}$ overnight. Plates were then blocked with $3 \%$ BSA (Kirkegaard and Perry Labs, Gaithersburg, MD) in PBS for $2 \mathrm{~h}$ at room temperature (RT) and supernatant (100 $\mu \mathrm{l}$ of culture supernatant) and standards of IL-4 (R\&D Systems, Gaithersburg, MD) (21-1,667 pg/ml) were added and incubated at $4^{\circ} \mathrm{C}$ overnight. Plates were washed and detecting biotinylated $\mathrm{mAb}$ (Pharmingen) were added to plates at 0.5 $\mu \mathrm{g} / \mathrm{ml}$ and incubated for $1 \mathrm{~h}$ at RT. After washing, the plates were incubated for 45 min with avidin-peroxidase (Sigma Chemical Co.) at a 1:2,000 dilution. After washing, plates were developed with TMB one component peroxidase substrate (KPL), and reactions were stopped by TMB one component stop solution (KPL). Absorbance was measured using ELISA reader (Bio-Rad, Melville, NY) at $450 \mathrm{~nm}$, and standard curve for each assay was generated, and cytokine production from each line was calculated. IFN- $\gamma$ was measured using a mouse monoclonal anti-human IFN- $\gamma$ at $1 \mu \mathrm{g} / \mathrm{ml}$ as coating antibody, a rabbit anti-human IFN- $\gamma$ polyclonal antibody at $1 \mu \mathrm{g} / \mathrm{ml}$ for secondary antibody (both from Endogen, Cambridge, MA), followed by a goat anti-rabbit-immunoglobulin-horseradish peroxidase-labeled antibody at 1:20,000 (Biosource International, Camarillo, CA). The 
IFN- $\gamma$ standard was purchased from GIBCO BRL, Gaithersburg, MD. Human TGF- $\beta 1$ was measured by a TGF- $\beta 1$ ELISA kit (Promega Corp., Madison, WI). Cytokine production from each line, performed in duplicate, was calculated by subtracting antigen-negative cytokine production from antigen-positive cytokine production. A line was considered positive if the antigen-specific cytokine secretion was $>50$ $\mathrm{pg} / \mathrm{ml}$ of IL-4 and $>100 \mathrm{pg} / \mathrm{ml}$ of IFN- $\gamma$ or TGF- $\beta 1$. The lowest measurable concentration for each assay was $5 \mathrm{pg} / \mathrm{ml}$ for IL-4, $10 \mathrm{pg} / \mathrm{ml}$ for IFN- $\gamma$, and $16 \mathrm{pg} / \mathrm{ml}$ for TGF- $\beta 1$.

Statistics analyses. A nonpaired two-tailed Student's $t$ test was used to perform the statistical analyses.

\section{Results}

Frequency of antigen-specific T cell lines and correlation of proliferation with cytokine production. The frequency of antigenreactive $\mathrm{T}$ cell lines from myelin-treated and non-myelintreated MS patients' PBMCs was determined by ${ }^{3} \mathrm{H}$-thymidine incorporation. A $\mathrm{T}$ cell line was considered positive when the stimulation index was $>3.0$ and the delta CPM was $>500$. A comparison of the frequencies in responses of the two groups to individual antigens is shown in Table I. Although there was a lower frequency of MBP- and PLP-reactive T cells in the myelin-treated group as compared to the nontreated group in response to MBP and PLP, this difference did not reach statistical significance in this cross-sectional analysis. The frequency of TT reactive lines were similar in both myelin-treated and nontreated groups.

Reactivity of human T cells is usually measured by ${ }^{3} \mathrm{H}$-thymidine incorporation. Thus it was important to know if this measure of $\mathrm{T}$ cell proliferation correlated with cytokine secretion. This was examined by screening several hundred lines (both negative and positive for antigen-induced ${ }^{3} \mathrm{H}$-thymidine incorporation) for secretion of IL-4, IFN- $\gamma$, and TGF- $\beta 1$ by ELISA. Although a correlation between thymidine uptake and IFN- $\gamma$ secretion was found (correlation coefficient $r=$ $0.60, P=0.0004$ ), there was no correlation between stimulation index and cytokine secretion for IL-4 and TGF- $\beta 1$. Thus, we measured cytokine secretion from all wells whether or not there was antigen-specific ${ }^{3} \mathrm{H}$-thymidine incorporation.

The relative frequency of cytokine-secreting lines. The relative frequency of cytokine-secreting lines in response to MBP, PLP, and TT in T cell lines from oral myelin-treated and nontreated patients was calculated for individual subjects, and the mean relative frequency for each group was calculated (Fig. 1). There was an increase in TGF- $\beta 1-$ secreting lines recognizing
MBP in the oral myelin-treated as compared to nontreated patients (myelin treated 9.9 \pm 2 , nontreated 1.3 $\pm 0.5, P<0.001$ ) (Fig. $1 A$ ). We also observed an increase in the relative frequency of IL-4-secreting lines reactive to MBP in the oral myelin-treated MS patients, but this did not reach statistical significance (myelin-treated 6.5 \pm 2.7 , nontreated 1.3 $\pm 0.7, P<$ $0.099)$. No difference in the relative frequency of IFN- $\gamma$ secret-

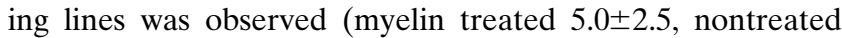
$6.4 \pm 1.8$ ). In response to PLP, there was also a significant increase in the relative frequency of TGF- $\beta 1-$ secreting $T$ cell lines in the myelin-treated group (myelin treated 9.5 \pm 2.2 , nontreated $1.1 \pm 0.7, P<0.003)$ while there were no differences observed for IL-4 secreting lines (myelin treated 3.1 \pm 1.9 , nontreated $2 \pm 1.6$ ) (Fig. $1 B$ ). There was a trend for lower IFN- $\gamma$ secretion from the oral myelin-treated group in response to PLP, but this did not achieve statistical significance (myelin treated $6.1 \pm 2.5$, nontreated $13.7 \pm 7.4, P<0.264)$. The frequency of TGF- $\beta 1$ secreting lines from individual subjects is shown in Fig. 2.

To examine whether the frequency of TGF- $\beta 1$ secreting lines from the oral myelin-treated group was specific for myelin antigens, we measured cytokine secretion from $\mathrm{T}$ cell lines using TT as a control antigen. Both oral myelin-treated and non-myelin treated groups showed similar relative frequencies of TGF- $\beta 1$, IL- 4 , and IFN- $\gamma$ cell lines in response to TT (TGF$\beta 1$; myelin treated $1.9 \pm 1.2$, nontreated $2.0 \pm 1.2$, IL-4; myelin treated $1.0 \pm 0.5$, nontreated 0 , IFN- $\gamma$; myelin treated $39.8 \pm 12.1$, nontreated 65.8 \pm 6.3 ) (Fig. $1 C$ ).

Th1- or Th2-, Th3-like cytokine secretion patterns. We analyzed individual $\mathrm{T}$ cell lines to determine whether high TGF- $\beta 1$ secretion was predominantly associated with IL-4 or IFN- $\gamma$ secretion. The majority of MS patients, whether or not receiving oral myelin, did not exhibit high relative frequencies of IL-4-secreting $\mathrm{T}$ cells. However, two individuals with relatively high frequencies of IL-4-secreting T cells were observed in the oral myelin-treated group. In both individuals, the IL-4secreting T cells predominantly secreted TGF- $\beta 1$ and not IFN- $\gamma$. The data for one of the two patients as compared to the nonmyelin-treated MS patient analyzed in the same experiment is shown in Fig. 3. Thus, the majority of TGF- $\beta 1-$ secreting $\mathrm{T}$ cells did not secrete IL-4 and are consistent with a distinct $\mathrm{CD}^{+}$Th3 cell type (20).

Correlation between the relative frequencies of $M B P$ vs. PLP TGF- $\beta 1$-secreting T cells. The frequency of both MBP and PLP reactive TGF- $\beta 1-$ secreting T cells varied among MS

Table I. Relative Frequency of Antigen-reactive T Cell Lines in MS Patients*

\begin{tabular}{|c|c|c|c|c|c|c|}
\hline & $\begin{array}{c}\text { No. of } \\
\text { MBP-reactive lines/ } \\
\text { total No. of lines }\end{array}$ & $\begin{array}{c}\text { Mean frequency } \\
\text { of MBP-reactive } \\
\text { wells }\end{array}$ & $\begin{array}{c}\text { No. of } \\
\text { PLP-reactive lines/ } \\
\text { total No. of lines }\end{array}$ & $\begin{array}{c}\text { Mean frequency } \\
\text { of PLP-reactive } \\
\text { wells }\end{array}$ & $\begin{array}{l}\text { No. of } \\
\text { TT-reactive lines/ } \\
\text { total No. of lines }\end{array}$ & $\begin{array}{c}\text { Mean frequency } \\
\text { of TT-reactive } \\
\text { wells }\end{array}$ \\
\hline & & $\%$ & & $\%$ & & $\%$ \\
\hline Myelin orally & & $1.3 \pm 0.5$ & & $3.7 \pm 1.0$ & & $23.3 \pm 9.0^{\ddagger}$ \\
\hline administered & $14 / 1,020$ & $(n=17)$ & $37 / 1,020$ & $(n=17)$ & $112 / 480$ & $(n=8)$ \\
\hline & & $3.4 \pm 2.5$ & & $7.6 \pm 3.6$ & & $19.0 \pm 8.9$ \\
\hline Control & $34 / 1,020$ & $(n=17)$ & $65 / 1,020$ & $(n=17)$ & $57 / 300$ & $(n=5)$ \\
\hline
\end{tabular}

*PBMC were plated directly into 96-well plates and stimulated with antigens as described in Methods. Each well was restimulated in the presence of antigen with APC on day 7 and for reactivity by a split well assay on day 14 . ${ }^{\ddagger}$ The values are expressed as the percentage of antigen reactive lines out of total generated lines. The results are expressed as the mean $\pm \mathrm{SE}$. 

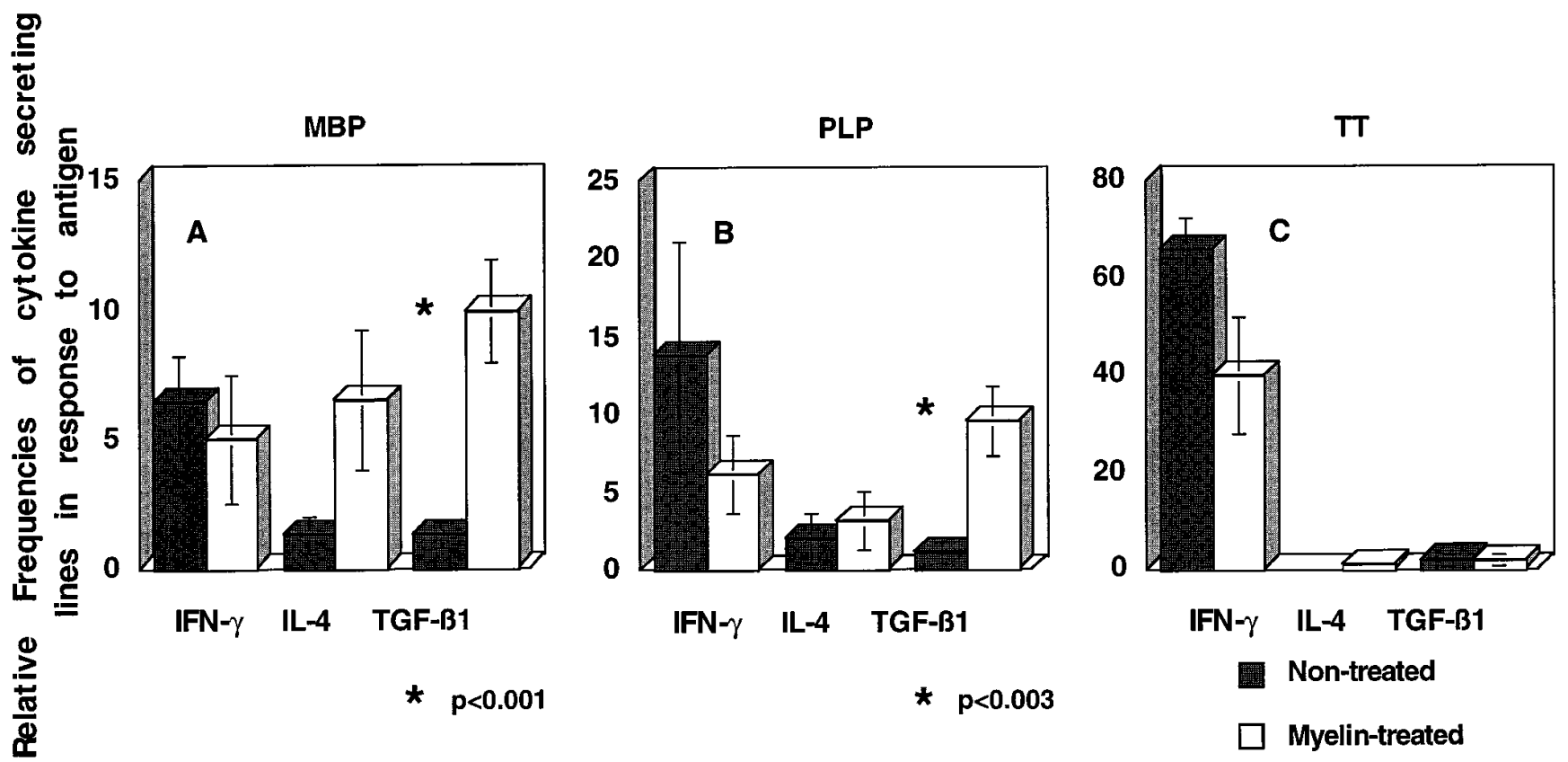

Figure 1. Relative frequency of antigen-reactive T cell lines secreting IL-4, IFN- $\gamma$, or TGF- $\beta 1$ from MS patients either receiving myelin orally or controls. The difference in cytokine secretion on day 14 of T cell lines stimulated by antigen-pulsed APCs were compared to T cell lines stimulated with APCs alone, as described in Methods. Culture supernatants were collected 24 hours after antigenic stimulation for an IL-4 and IFN- $\gamma$ ELISA. Serum-free media was added to each well, and after an additional $72 \mathrm{~h}$, culture supernatant was collected for a TGF- $\beta 1$ ELISA. A line was considered positive if the antigen-specific cytokine secretion was $>50 \mathrm{pg} / \mathrm{ml}$ of IL-4 and $>100 \mathrm{pg} / \mathrm{ml}$ of IFN- $\gamma$ or TGF- $\beta 1$. The relative frequencies of cytokine-secreting lines with antigenic stimulation were calculated for each patient, 17 myelin-treated and 17 nontreated patients and the average values, \pm standard errors, are shown here. Significant $P$ values for TGF- $\beta 1$ secretion are highlighted in bold. ( $A$ ) MBP stimulation. TGF- $\beta 1$, myelin treated 9.9 \pm 2 , nontreated 1.3 $\pm 0.5, P<\mathbf{0 . 0 0 1}$; IL-4, myelin-treated $6.5 \pm 2.7$, nontreated $1.3 \pm 0.7, P<0.099 ;$ IFN- $\gamma$, myelin treated 5.0 \pm 2.5 , nontreated 6.4 \pm 1.8 . (B) PLP stimulation. TGF- $\beta 1$, myelin treated $9.5 \pm 2.2$, nontreated $1.1 \pm 0.7, \boldsymbol{P}<\boldsymbol{\mathbf { 0 . 0 0 3 }}$; IL-4, myelin treated $3.1 \pm 1.9$, nontreated $2 \pm 1.6$; IFN- $\gamma$, myelin treated $6.1 \pm 2.5$, nontreated $13.7 \pm 7.4, P<0.264$. (C) TT stimulation. TGF- $\beta 1$, myelin treated $1.9 \pm 1.2$, nontreated $2.0 \pm 1.2$; IL-4, myelin treated $1.0 \pm 0.5$, nontreated 0 , IFN- $\gamma$, myelin treated $39.8 \pm 12.1$, nontreated $65.8 \pm 6.3$, all values not significantly different for TT stimulation.
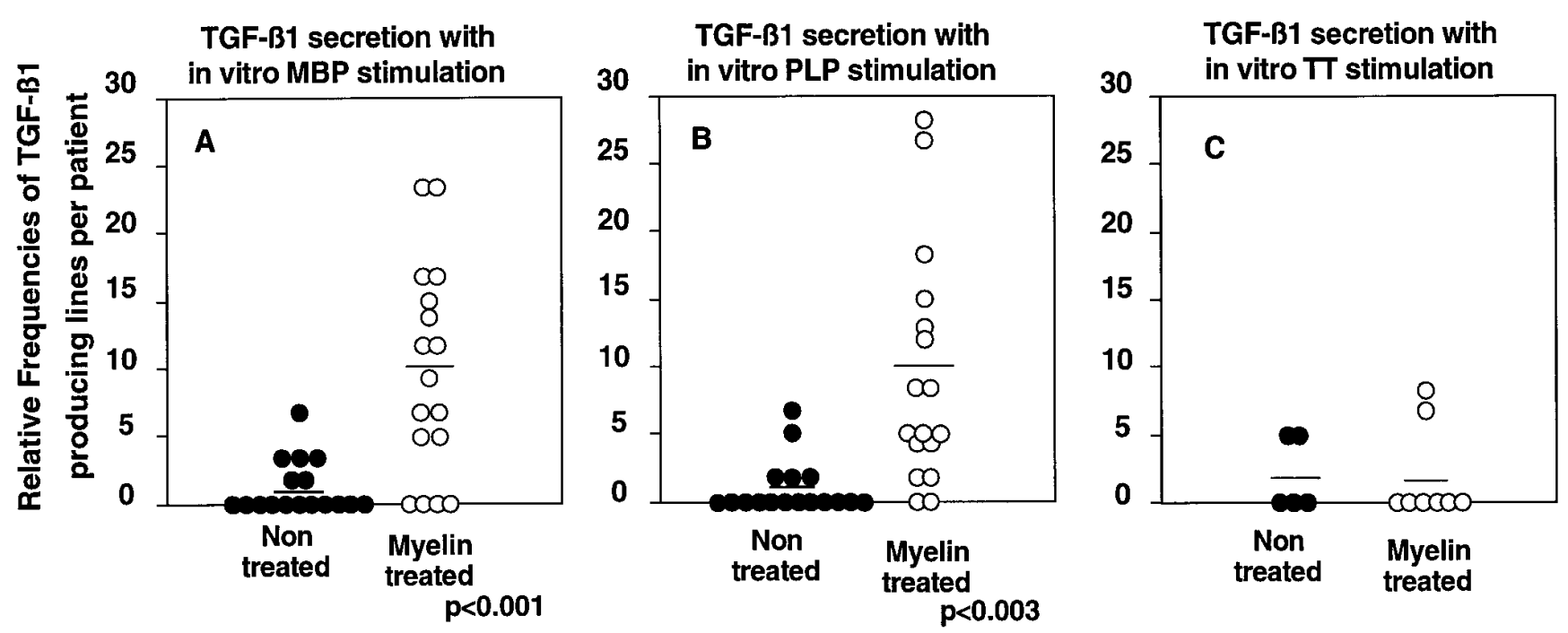

Figure 2. Distribution of relative frequencies of TGF- $\beta 1$-producing lines in response to antigen. PBMC were stimulated with antigens (MBP, PLP, and TT) and cultured as described. $24 \mathrm{~h}$ after antigen stimulation on day 14, culture media were replaced with serum-free media, and cells were cultured for an additional $72 \mathrm{~h}$. TGF- $\beta 1$ secretion in supernatant was measured by ELISA. Each data point represents a patient sample and indicates percentage of positive cytokine-producing lines out of total generated lines. $(A)$ MBP, $(B)$ PLP, $(C)$ TT. There were significantly more TGF- $\beta 1$-secreting lines generated from treated patients than nontreated patients $(\boldsymbol{P}<\mathbf{0 . 0 0 1}$ and $\boldsymbol{P}<\boldsymbol{0 . 0 0 3}$ for MBP and PLP-reactive T cell lines, respectively). 


\section{Non-treated}
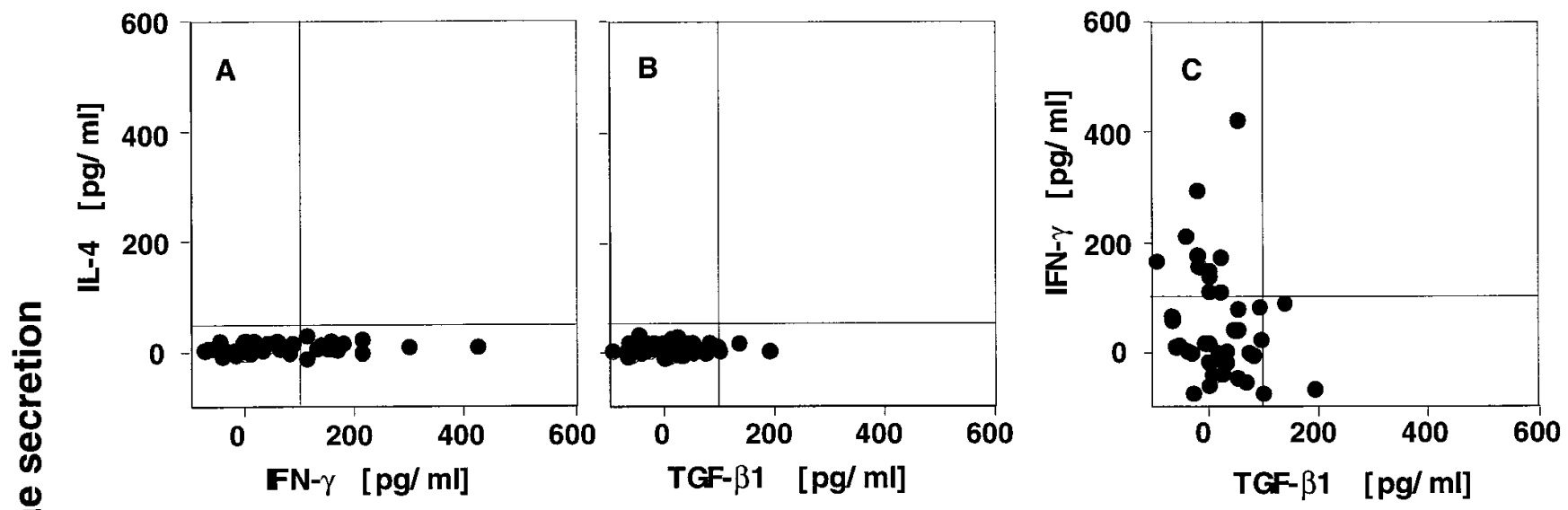

\section{Oral myelin-treated}
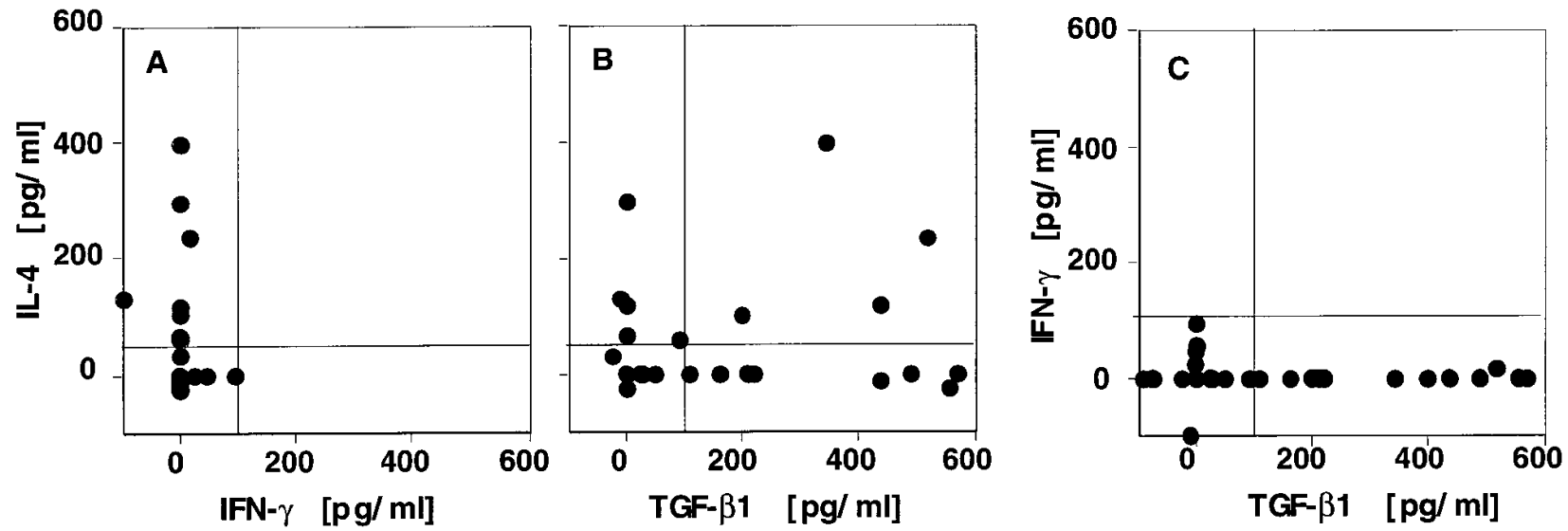

Figure 3. TGF- $\beta 1$ secretion is associated with IL-4, not IFN- $\gamma$-secreting T cells. Cytokine production by MBP-specific T cell lines generated from one of two oral myelin-treated patients generating significant numbers of IL-4-secreting T cells and one concurrently examined nontreated patient. ( $A$ ) IL-4 versus IFN- $\gamma ;(B)$ IL-4 versus TGF- $\beta 1 ;(C)$ IFN- $\gamma$ versus TGF- $\beta 1$. Cytokine production in supernatant from single T cell lines in response to MBP is represented by each data point. In this representative patient set, $\mathrm{T}$ cell lines from a nontreated patient secreted IFN- $\gamma$ or small amounts of TGF- $\beta 1$ and no IL-4; lines generated from an oral myelin-treated patient secreted IL-4 or TGF- $\beta 1$ and IL-4, but not IFN- $\gamma$ and TGF- $\beta 1$.

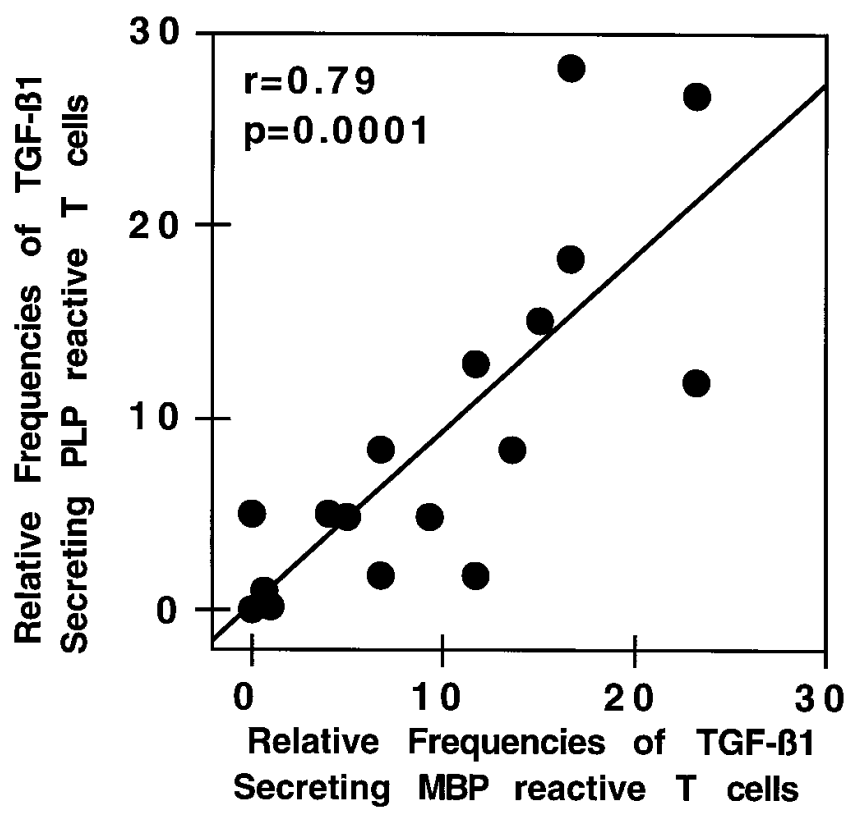

patients orally treated with myelin. This led us to examine whether there was a correlation between the relative frequencies of MBP vs. PLP TGF- $\beta 1-$ secreting T cells among individual subjects. As is shown in Fig. 4, there was a highly significant correlation in individual patients between the frequency of MBP vs. PLP TGF- $\beta 1-$ secreting T cells.

\section{Discussion}

The present study was carried out to determine whether the prolonged oral administration of myelin in MS patients alters the frequency or cytokine secretion patterns of MBP or PLP

Figure 4. Correlation between the relative frequencies of MBP vs. PLP TGF- $\beta 1-$ secreting T cells. The relative frequencies of MBP vs. PLP TGF- $\beta 1$-secreting T cells among individual subjects were correlated by a linear-regression analysis. There was a significant correlation $(r=0.79, P=0.0001)$ in individual patients between the relative frequency of MBP vs. PLP TGF- $\beta 1-$ secreting T cells. 
reactive T cells. Here, we demonstrate an increase in the frequency of MBP and PLP but not TT reactive TGF- $\beta 1$-secreting $\mathrm{T}$ cell lines in myelin-treated MS patients as compared to non-myelin-treated MS patients. These data, showing cytokine deviation with antigen-specific immunotherapy in subjects with autoimmune disease, have not been previously reported and are consistent with our observation that in mice receiving oral MBP, there is an increase in MBP-specific TGF- $\beta 1$ secreting T cells.

A number of studies have defined mechanisms by which oral tolerization occurs in rodents. Investigations of the EAE model have shown that one of the primary mechanisms involves the generation of active suppression, and this is mediated by $\mathrm{T}$ cells that secrete TGF- $\beta 1$ and suppress the immune response (27). Furthermore, $\mathrm{T}$ cell clones isolated from the mesenteric lymph nodes of mice orally tolerized with MBP secreting IL-4, IL-10, and TGF- $\beta 1$ suppressed ongoing EAE induced by either MBP or PLP (20). The regulatory properties of these $\mathrm{T}$ cell clones were abrogated when mice were given anti-TGF- $\beta 1$ antibodies, suggesting a critical role for local secretion of TGF- $\beta 1$ in suppressing the immune response. Similar cytokine patterns were observed in MBP T cell receptor transgenic mice orally tolerized with low doses of MBP (21). The importance of cytokines in regulating the inflammatory CNS response in EAE has also been suggested by immunopathologic examination of cytokine secretion in the CNS. Animals with acute EAE exhibit perivascular infiltration with activated mononuclear cells secreting the inflammatory cytokines IL-1, IL-2, TNF- $\alpha$, IFN- $\gamma$, IL-6, and IL-8. In contrast, animals with EAE that had been orally tolerized with MBP exhibit a marked reduction of the perivascular infiltrate, with down regulation of inflammatory cytokines and increased amounts of TGF- $\beta 1$ and IL-4 (6). These results suggest that the suppression of EAE, by oral tolerization and natural recovery, is related to regulatory cells that secrete inhibitory cytokines at the target organ.

We examined TGF- $\beta 1$ secretion from $T$ cell lines using irradiated whole mononuclear cells as antigen-presenting cells (APC). The secretion of TGF- $\beta 1$ by $T$ cell lines cultured with the APC in the absence of antigen was compared to that of lines stimulated with APC pulsed with antigen. No TGF- $\beta 1$ could be detected in supernatants at 48 or $96 \mathrm{~h}$ after the addition of antigen to the culture of either fresh PBMC or Mo1positive macrophages from treated subjects, indicating that macrophages or other APCs did not directly secrete TGF- $\beta 1$ without $\mathrm{T}$ cell help (data not shown). However, as macrophages and other APCs are capable of secreting TGF- $\beta 1$, we cannot rule out that T cells, activated by antigen, signaled APC to secrete TGF- $\beta 1$. Further analysis of the TGF- $\beta 1-$ secreting cell population is limited both by the unavailability of reagents to perform intracytoplasmic staining for this cytokine, and the low cell numbers hampering isolation of $\mathrm{T}$ cell populations at the early time points when cytokines are measured. While it is clear that the $\mathrm{T}$ cell lines are stimulated by antigen and thus presumably are secreting TGF- $\beta 1$, it should be noted that the identity of the cytokine secreting cells has not been formally demonstrated.

TGF- $\beta 1$ has a number of properties consistent with a role in regulating the immune response. It is potent in inhibiting $\mathrm{T}$ and $B$ cell entry into $S / G_{2} / M$ cell cycle and thus inhibiting proliferation. Paradoxically, TGF- $\beta 1$ also can attract macrophages to sites of inflammation while inducing upregulation of IgA se- cretion by activated B lymphocytes. TGF- $\beta 1$ can also induce fibrin deposition and is involved in scar formation $(28,29)$. Thus the combined physiologic action of TGF- $\beta 1$ may be to down-regulate inflammatory $\mathrm{T}$ cell responses while inducing tissue repair.

The oral administration of antigen is a well known method in experimental animals of inducing tolerance to prevent systemic immune reactions $(7,8,30)$. However, there are few investigations in humans regarding the mechanism of oral tolerization. The immune responses in normal individuals orally administered $50 \mathrm{mg}$ KLH daily for 2 wk over a 3-wk period decreased subsequent cell-mediated immune responses when subjects were injected with KLH, although antibody responses were not affected (31). The mechanism for this suppression has not been elucidated. Myelin antigens have also been given by other routes in attempts to tolerize human $\mathrm{T}$ cell responses. Porcine MBP was previously administered to patients with MS with subsequent examination of immune sensitization (32). These studies showed that with parenteral administration of MBP, subsequent delayed type hypersensitivity responses were observed, presumably representing a Th1 type response.

In our study, we measured responses to human rather than bovine MBP while we orally administered bovine myelin. Examination of one and not both MBP antigens was restricted by the amount of blood we could obtain from the patients. Though the immunodominant epitope (residues 84-102) of MBP are identical between human and bovine $\operatorname{MBP}(1,2)$, there are sequence differences in other parts of the protein. We believe examination of the response to human MBP is of greater clinical importance as, ultimately, we are interested in generating TGF- $\beta 1-$ secreting $\mathrm{T}$ cell clones that recognize human proteins in the CNS. This is not an issue with PLP as the sequence between human and bovine PLP is almost identical.

We previously reported that the frequency of MBP-reactive $T$ cells was significantly decreased in a longitudinal study investigating frequencies before and after initiating oral administration of myelin in patients with MS (22). While a similar trend was observed in the present study, the data did not reach statistical significance. We believe the lack of statistical significance in the present cross-sectional study is related to the variability in the frequency of MBP reactive T cells among different patients with MS as compared to the serial measurements we performed in our first investigation. A longitudinal study of the frequency and cytokine secretion patterns of MS patients is in progress. Although the patients were being followed in an open label, nonrandomized fashion, we attempted to determine whether there was a correlation between frequency of TGF- $\beta 1$-secreting cells and response to therapy by arbitrarily dividing patients into responders and nonresponders and performing a chi-square statistical analysis. No correlation was found in this small number of patients studied. As mentioned above, this will be examined in a larger study powered to address this experimental question.

Feeding a single high dose of antigen induces anergy of antigen-specific Th1 cells or clonal deletion, when multiple low doses of antigen induces regulatory $\mathrm{T}$ cells that mediate disease by producing immunosuppressive cytokines $(16,20,21)$. In this study, MS patients were treated with $300 \mathrm{mg}$ of bovine myelin daily. While we could demonstrate the presence of MBP and PLP-reactive T cells secreting TGF- $\beta 1$, the present investigation does not allow us to determine precisely where this amount of oral myelin falls on the dose response curve. 
Thus, as mentioned above, a longitudinal dosing trial is in progress to address this question.

As expected from treating an outbred group of MS patients, there was a distribution in the range of both MBP and PLP reactive TGF- $\beta 1-$ secreting T cells. This may have been due to differences among individual patients in their ability to recognize these myelin antigens, or alternatively, individual patients may have differential abilities to generate TGF- $\beta 1$ secreting $\mathrm{T}$ cells. This question was addressed by determining whether there was a correlation among individual patients in the frequencies of MBP vs. PLP reactive TGF- $\beta 1$-secreting T cells. Indeed we found a highly significant correlation in individual MS patients between the frequency of these two myelin-reactive $\mathrm{T}$ cell populations. As MBP and PLP-reactive TGF- $\beta 1$-secreting $T$ cells were found in the same patients, these data suggest the later hypothesis that individual patients, similar to different mice strains, may have a differential ability to generate different cytokine secreting populations of $\mathrm{T}$ cells.

While MBP and PLP are the most abundant proteins in the central nervous system myelin and may represent major targets of the putative cell-mediated autoimmune response, other antigens such as MOG (5), and S100 beta (33), are also candidate antigens to induce effector T cells which may be of critical importance in the pathogenesis of MS. Moreover, Sercarz and co-workers have defined the concept of immunodominant and cryptic antigens in mice based on recognition of peptides after primary in vivo stimulation with either whole protein antigen or peptides, respectively (34). Thus while the T cell response may be initially focused on immunodominant epitopes, with time there is spreading to other cryptic epitopes or other tissue antigens recognized by $\mathrm{T}$ cells. This concept is supported by studies of patients with MS where an increased frequency of activated T cells is found to both MBP and PLP in the same patients (35). Together, these data indicate that while tolerization to a single protein epitope or antigen in animals may effectively ameliorate experimental models of autoimmunity early in the course of the disease, immune therapy for T cellmediated chronic human autoimmune disease such as MS or type I diabetes will require approaches that suppress ongoing immune responses to a multitude of organ-associated self antigens. The use of oral myelin tolerization to generate MBP and PLP-reactive T cells in humans that have the ability to migrate into the central nervous system and nonspecifically suppress ongoing autoimmune responses at the target organ by secreting TGF- $\beta 1$ represents an antigen-specific immunotherapy capable of suppressing autoimmune responses to multiple self antigens at the target organ. Moreover, these data show that autoantigen-specific $T$ cells secreting TGF- $\beta 1$ can be generated in humans with a putative autoimmune disease.

In summary, oral administration of myelin to MS patients generates an increased frequency of MBP and PLP-specific TGF- $\beta 1-$ secreting $T$ cells. These results are consistent with the cytokine secretion profile of regulatory $\mathrm{T}$ cells in animals after oral tolerization with MBP (19-21, 27). Such antigen-specific regulatory $\mathrm{T}$ cells, upon homing to the central nervous system, would be predicted to suppress ongoing autoimmune immune responses in an antigen nonspecific fashion by the secretion of TGF- $\beta 1$, a mechanism which has been termed bystander suppression. $\mathrm{T}$ cells induced by mucosal stimulation with antigen which secrete TGF- $\beta 1$ appear to represent a distinct lineage of T cells (Th3) (36). Our data demonstrated that oral tolerization with self antigens in a human autoimmune disease may pro- vide a therapeutic approach to the treatment of autoimmune disease which does not depend upon knowledge of the antigen specificity of the original $\mathrm{T}$ cell clone triggering the autoimmune cascade.

\section{Acknowledgments}

This work was supported by National Institutes of Health grants RO1-NS24247 (D.A. Hafler), RO1-NS-29352 (H.L. Weiner), Program Project Grant AR 43220 (D.A. Hafler and H.L. Weiner), and grants from The National Multiple Sclerosis Society (H.L. Weiner, D.A. Hafler), and AutoImmune Inc., Lexington, MA. Drs. Hafler and Weiner have a financial interest in AutoImmune, Inc.

\section{References}

1. McFarlin, D.E., and H.F. McFarland. 1982. Multiple sclerosis. N. Engl. J. Med. 307:1183-1188.

2. Hafler, D.A., and H.L. Weiner. 1995. Immunologic mechanisms and therapy in multiple sclerosis. Immunol. Reviews. 144:75-107.

3. Zamvil, S., P. Nelson, J. Trotter, D. Mitchell, R. Knobler, R. Fritz, and L. Steinman. 1985. T cell clones specific for myelin basic protein induce chronic relapsing paralysis and demyelination. Nature (Lond.). 317:355-358.

4. Tuohy, V.K., R.A. Sobel, and M.B. Lees. 1988. Myelin proteolipid protein-induced experimental allergic encephalomyelitis. Variations of disease expression in different strains of mice. J. Immunol. 140:1868-1873.

5. Linington, C., T. Berger, L. Perry, S. Weerth, D. Hinze-Selch, Y. Zhang, H.C. Lu, H. Lassmann, and H. Wekerle. 1993. T cells specific for the myelin oligodendrocyte glycoprotein mediate an unusual autoimmune inflammatory response in the central nervous system. Eur. J. Immunol. 23:1364-1372.

6. Khoury, S.J., W.W. Hancock, and H.L. Weiner. 1992. Oral tolerance to myelin basic protein and natural recovery from experimental autoimmune encephalomyelitis are associated with downregulation of inflammatory cytokines and differential upregulation of transforming growth factor- $\beta$, interleukin- 4 , and prostaglandin E expression in the brain. J. Exp. Med. 176:1355-1364.

7. Chase, M.W. 1946. Inhibition of experimental drug allergy by prior feeding of the sensitizing agent. Proc. Soc. Exp. Biol. Med. 61:257-259.

8. Mowat, A.M. 1987. The regulation of immune responses to dietary protein antigens. Immunol. Today. 8:93-98.

9. Higgins, P.J., and H.L. Weiner. 1988. Suppression of experimental autoimmune encephalomyelitis by oral administration of myelin basic protein and its fragments. J. Immunol. 140:440-445.

10. Bitar, D.M., and C.C. Whitacre. 1988. Suppression of experimental autoimmune encephalomyelitis by the oral administration of myelin basic protein. Cell. Immunol. 112:364-370.

11. Thompson, H.S., and N.A. Staines. 1986. Gastric administration of type II collagen delays the onset and severity of collagen-induced arthritis in rats. Clin. Exp. Immunol. 64:581-586.

12. Nagler-Anderson, C., L.A. Bober, M.E. Robinson, G.W. Siskind, and G.J. Thorbecke. 1986. Suppression of type II collagen-induced arthritis by intragastric administration of soluble type II collagen. Proc. Natl. Acad. Sci. USA. 83:7443-7446.

13. Zhang, Z.J., C.S.Y. Lee, O. Lider, and H.L. Weiner. 1990. Suppression of adjuvant arthritis in Lewis rats by oral administration of type II collagen. $J$. Immunol. 145:2489-2493.

14. Nussenblatt, R.B., R.R. Caspi, R. Mahdi, C.-C. Chan, F. Roberge, O. Lider, and H.L. Weiner. 1990. Inhibition of S-antigen induced experimental autoimmune uveoretinitis by oral induction of tolerance with S-antigen. J. Immunol. 144:1689-1695.

15. Zhang, Z.J., L. Davidson, G. Eisenbarth, and H.L. Weiner. 1991. Suppression of diabetes in nonobese diabetic mice by oral administration of porcine insulin. Proc. Natl. Acad. Sci. USA. 88:10252-10256.

16. Chen, Y., J.-I. Inobe, R. Marks, P. Gonnella, V.K. Kuchroo, and H.L. Weiner. 1995. Peripheral deletion of antigen-reactive T cells in oral tolerance. Nature (Lond.). 376:177-180.

17. Whitacre, C.C., I.E. Gienapp, C.G. Orosz, and D.M. Bitar. 1991. Oral tolerance in experimental autoimmune encephalomyelitis. III. Evidence for clonal anergy. J. Immunol. 147:2155-2163.

18. Friedman, A., and H.L. Weiner. 1994. Induction of anergy or active suppression following oral tolerance is determined by antigen dosage. Proc. Natl. Acad. Sci. USA. 91:6688-6692.

19. Miller, A., O. Lider, and H.L. Weiner. 1991. Antigen-driven bystander suppression following oral administration of antigens. J. Exp. Med. 174:791798.

20. Chen, Y., V.K. Kuchroo, J.-I. Inobe, D.A. Hafler, and H.L. Weiner. 1994. Regulatory T cell clones induced by oral tolerance: suppression of autoimmune encephalomyelitis. Science (Wash. DC). 265:1237-1240.

21. Chen, Y., J.-I. Inobe, V.K. Kuchroo, J.L. Baron, C.A. Janeway, Jr., and 
H.L. Weiner. 1996. Oral tolerance in myelin basic protein T-cell receptor transgenic mice: suppression of autoimmune encephalomyelitis and dose-dependent induction of regulatory cells. Proc. Natl. Acad. Sci. USA. 93:388-391.

22. Weiner, H.L., G.A. Mackin, M. Matsui, E.J. Orav, S.J. Khoury, D.M. Dawson, and D.A. Hafler. 1993. Double-blind pilot trial of oral tolerization with myelin antigens in multiple sclerosis. Science (Wash. DC). 259:1321-1324.

23. Trentham, D.E., R.A. Dynesius-Trentham, E.J. Orav, D. Combitchi, C. Lorenzo, K.L. Sewall, D.A. Hafler, and H.L. Weiner. 1993. Effects of oral administration of type II collagen on rheumatoid arthritis. Science (Wash. DC). 261:1727-1730.

24. Hohol, M.J., S.J. Khoury, S.L. Cook, E.J. Orav, D.A. Hafler, and H.L. Weiner. 1996. Three year open protocol continuation study of oral tolerization with myelin antigens in multiple sclerosis and design of a phase III pivotal trial. Annu. NY Acad. Sci. 778:243-250.

25. Chou, F.C.-H., C.-H.J. Chou, R. Shapira, and R.F. Kibler. 1976. Basis of microheterogeneity of myelin basic protein. J. Biol. Chem. 251:2671-2679.

26. Bizzozero, O.A., G. Zuniga, and M.B. Lees. 1991. Fatty acid composition of human myelin proteolipid protein in peroxisomal disorders. J. Neurochem. 56:872-878.

27. Miller, A., O. Lider, A.B. Roberts, M.B. Sporn, and H.L. Weiner. 1992. Suppressor $\mathrm{T}$ cells generated by oral tolerization to myelin basic protein suppress both in vitro and in vivo immune responses by the release of transforming growth factor $\beta$ after antigen-specific triggering. Proc. Natl. Acad. Sci. USA. 89: $421-425$.

28. Lebman, D.A., F.D. Lee, and R.L. Coffman. 1990. Mechanism for transforming growth factor $\beta$ and IL-2 enhancement of $\operatorname{IgA}$ expression in lipopolysaccharide-stimulated B cell cultures. J. Immunol. 144:952-959.
29. Wahl, S.M., N. McCarthy-Francis, and S.E. Mergenhagen. 1989. Inflammatory and immunomodulatory roles of TGFß. Immunol. Today. 10:258-261.

30. Weiner, H.L., A. Friedman, A. Miller, S.J. Khoury, A. Al-Sabbagh, L. Santos, M. Sayegh, R.B. Nussenblatt, D.E. Trentham, and D.A. Hafler. 1994. Oral tolerance: immunologic mechanisms and treatment of animal and human organ-specific autoimmune disease by oral administration of autoantigens. Annu. Rev. Immunol. 12:809-837.

31. Husby, S., J. Mestecky, Z. Moldoveanu, S. Holland, and C.O. Elson. 1994 Oral tolerance in humans: $\mathrm{T}$ cell but not B cell tolerance after antigen feeding. J. Immunol. 152:4663-4670.

32. Salk, R.J.S. 1983. A study of myelin basic protein as a therapeutic probe in patients with multiple sclerosis. In Multiple Sclerosis. J.F. Hallpike, C.W.M. Adams, and W.W. Tourtellotte, editors. Chapman and Hall, London. 621-630.

33. Kojima, K., T. Berger, H. Lassman, D. Hinze-Selch, Y. Zhang, J. Gehrmann, K. Reske, H. Wekerle, and C. Linington. 1994. Experimental autoimmune panencephalitis and uvoretinitis transferred to the Lewis rat by $\mathrm{T}$ lymphocytes specific for the S100-beta molecule, a calcium binding protein of astroglia. J. Exp. Med. 180:817-829.

34. Lehmann, P.V., T. Forsthuber, A. Miller, and E.E. Sercarz. 1992. Spreading of T-cell autoimmunity to cryptic determinants of an autoantigen. Nature (Lond.). 358:155-157.

35. Zhang, J., S. Markovic-Plese, B. Lacet, J. Raus, H.L. Weiner, and D.A. Hafler. 1994. Increased frequency of interleukin-2 responsive T cells specific for myelin basic protein and proteolipid protein in peripheral blood and cerebrospinal fluid of patients with multiple sclerosis. J. Exp. Med. 179:973-984.

36. Mosmann, T.R., and S. Sad. 1996. The expanding universe of T cell subsets: Th1, Th2 and more. Immunol. Today. 17:138-146. 